$T \cdot 1375$

$(\mathrm{SSC}-\mathrm{N}-111$ )

0102.000

\title{
QUENCH PROPAGATION DELAY DUE TO COPPER WEDGES
}

M. Kuchnir, A. D. MCInturff, R. W. Hanft, and P. O. Mazur

January 1986 
Quench Propagation Delay Due to Copper Wedges

M. Kuchnir, A.D. MeInturff, R.W. Hanft and P.O. Mazur

\section{INTRODUCTION}

The superconducting magnet design style selected for the SSC dipoles: is $16.6 \mathrm{~m}$ long and incorporates copper wedges in the windings in order to achieve the required magnetic fleld uniformity. Recent studies"3 of quench propagation in a 4 model, SLN-012 at BNL, have been carried out in order to prove the feasibility of self-protection for these magnets in the event of a quench. This feature would dispense with an active protection system like the one used in the Fermilab Energy Saver". These studies, however, require the knowledge of how the copper wedges affect the transverse spreading of normal zones needed in the self-protecting scheme. It is not clear that such information can be obtained with the short $(1 \mathrm{~m}$ long) prototypes about to be tested since the time for the normal zone to cross over a wedge might be of the order of or longer than the time it takes for it to reach the other side of the wedge by propagation along the cable.

Well instrumented long prototype magnets are months away from availability. Calculations that take into account the effect of the Kapton insulation, helium in the interstices and other significant details do not exist or have not been tested. Therefore we have measured the delay that the copper wedges introduce in the transverse (azimuthal) propagation of the normal zone in an experimental simulation of these magnets.

\section{EXPERIMENTAL SIMULATION}

A $0.15 \mathrm{~m}$ long model of the cross section of the magnet was assembled using the actual laminations, segments of cables and of copper wedges of the same length. Current carrying cables instead of $0.15 \mathrm{~m}$ inert segments were used around three of the wedges. Flgure 1 shows 


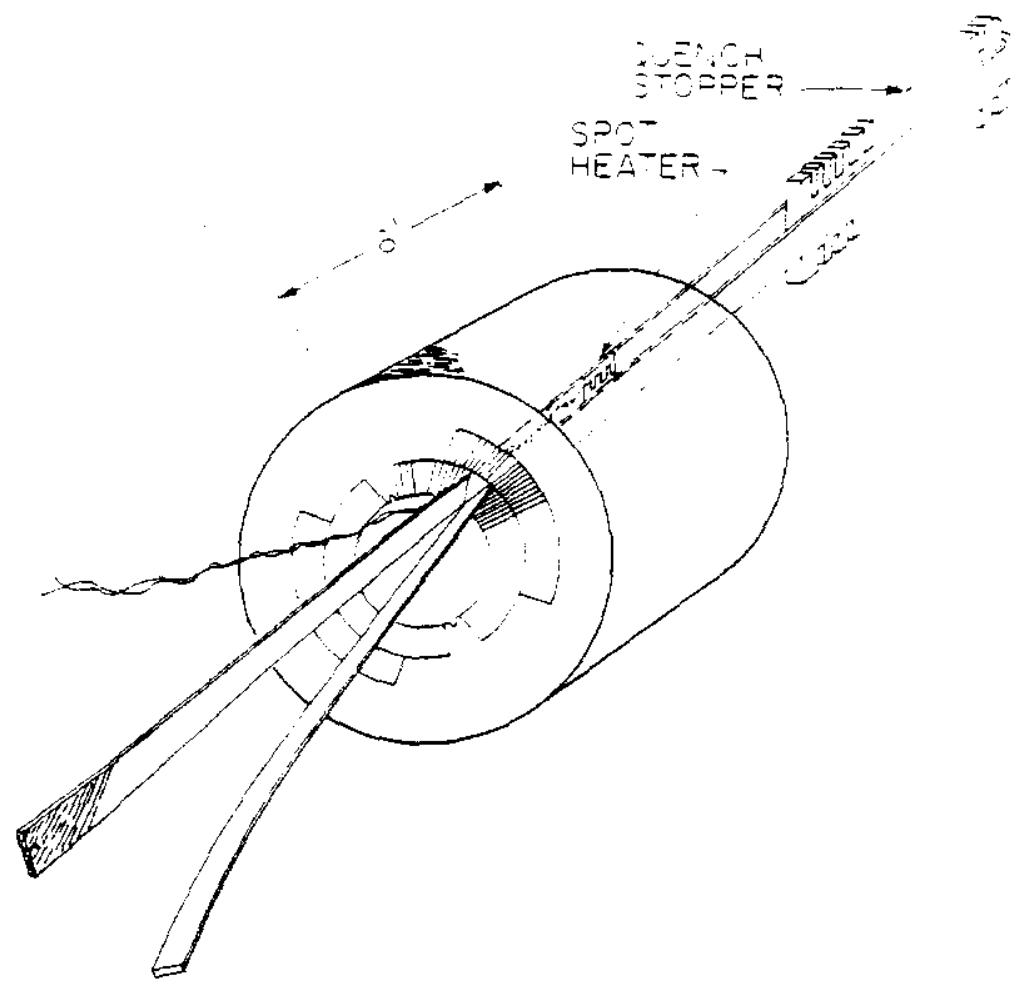

FIGURE 1

Sketch of Model Showing Cable Around Inner Coil Thin Wedge with its Spot Heater and Quench Stopper.

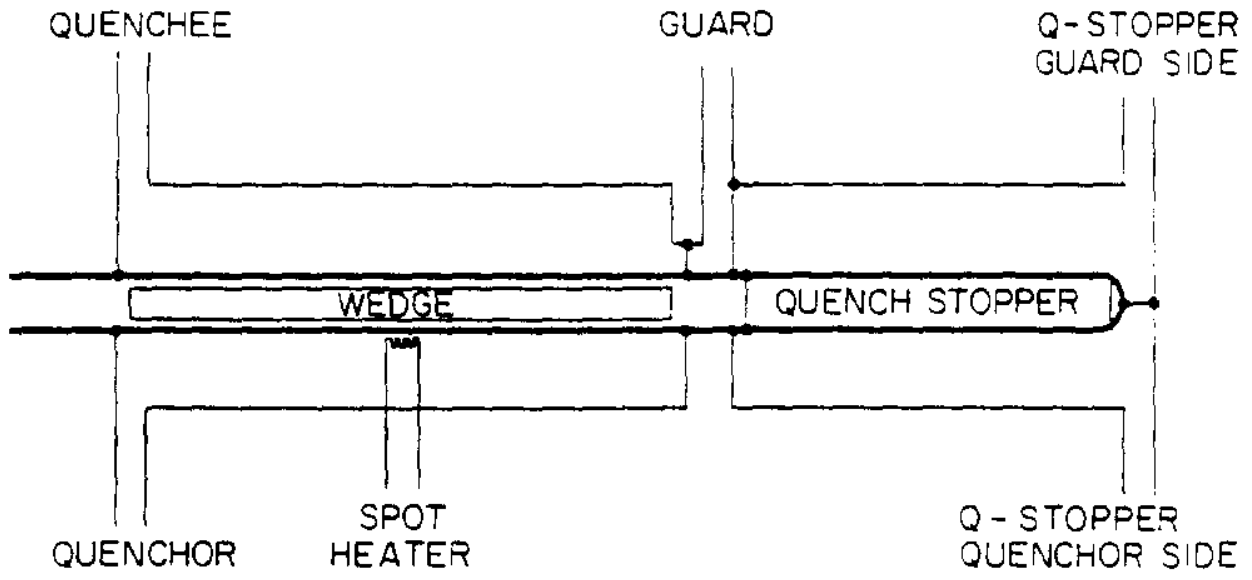

FIGURE 2

Voltage Taps Diagram 
only the cable around the inner coil thin wedge for simplicity. Spot heaters consisting of $350 \Omega$ strain gauges ${ }^{6}$ were inserted in the model next to the side of the active cable opposite the wedge and in the middle of the model. Figure 2 indicates schematically the position of voltage taps and quench-stoppers associated with each cable-wedge combination. We simplify the description of the test by labelling as "quenchor" the cable segment instrumented with the spot heater and "quenchee" the cable segment on the opposite side of the wedge. The test consisted of: establishing a steady current through the cable, firing the spot heater by applying from $10 \mathrm{~V}$ to $25 \mathrm{~V} \mathrm{DC}$, and recording the voltages across the quenchor, quenchee and the "guard" taps as functions of time. The guard going normal at the same time or after the quenchee is a verification that the quench propagated through the wedge and not through the quench-stopper. The quench-stopper is a solid copper slab $0.152 \mathrm{~m} \times 0.025 \mathrm{~m} \times 0.0063 \mathrm{~m}$ to whlch the cable is wrapped and sort-soldered. Grooves machined in its sides cause it to present a surface area of $0.01 \mathrm{~m}^{2}$ to the liquid He. The the cable types selected for the SSC were used to border the inner coll wedges (silver stranded BNL cable) and the outer coll wedge (black stranded LBL cable). The extremities of the wedges under test were heavily coated with a sealant? in order to reduce heat transfer to the liquid. This simulation of a magnet falls short of providing directly usefull data in three respects: It is done in a zero magnetic field background, the cable insulation (dry wound procedure) is not the one used in the SLN-012 prototype and just one cable per wedge side carries current.

Nevertheless, this data is relevant for establishing the order of magnitude of the delay and for testing computer simulations.

DATA ACQUISITION

The tests were carried out in Lab 2 using the assembly arranged for the testing of Energy Saver power leads and the quench data collection system developed for the M1O test backed up by a fast chart recorder.

In a preliminary test just the cable around the thick wedge of the inner coil was connected to the power leads. The data acquired in this test on Nov 20,1985 are in direct access Cyber flles labelled WEO1AOO to WE01A8/UN=94810. Six variables were recorded as a function of time: the current through the cable, the total voltage across the set up (including the power leads), the voltage drops across the quenchor, quenchee and guard as well as a signal indlcating current through the spot heater.

After connecting all three cables in series we repeated the measurements and these are stored in similar Cyber flles labeled from WE02A0O to WE02A33. Two more varlables were included in these measurements: the voltage difference across the guard side and the quenchor side of the quench-stoppers. Also the actual voltage across the spot heater instead of just an indlcative voltage was used. Elgure 3 shows chart recorder traces during a typlcal quench (No. 29). 


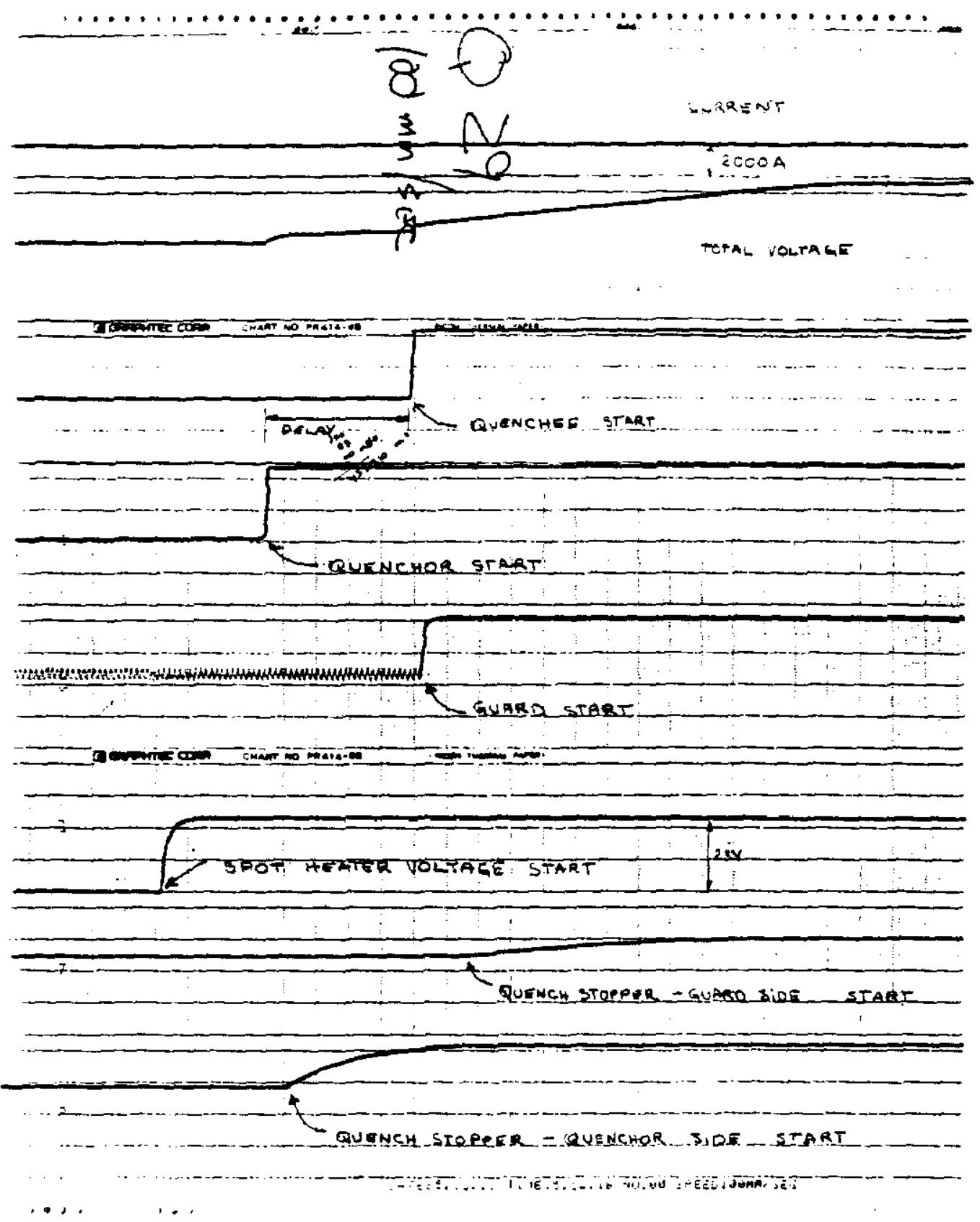

FIGURE 3

Chart Recorder Traces Showing Quench \#29 
The amplifiers used for the quenchor and quenchee voltages in the preliminary test had a time constant of $120 \mathrm{~ms}$ that prevented analysis of the data beyond measurement of the delay and made it dificult to see that the $6 \mathrm{kA}$ points had the guard starting before the quenchee. This was corrected in the main set of measurements by use of amplifiers with time constants less than 5 ms.

\section{RESULTS}

Typical digitized data is shown plotted in figures 4,5 and 6. They show voltages as a function of time at the start of quenches across the quenchor, quenchee and guard, respectively. Indicated in these plots are the starting times, voltages at the end of propagation and calculated propagation speed. Data obtained this way is presented in figure 7. This data is of a secondary relevance as $f a r$ as the purpose of this test which was to measure the delay shown in figure 8 .

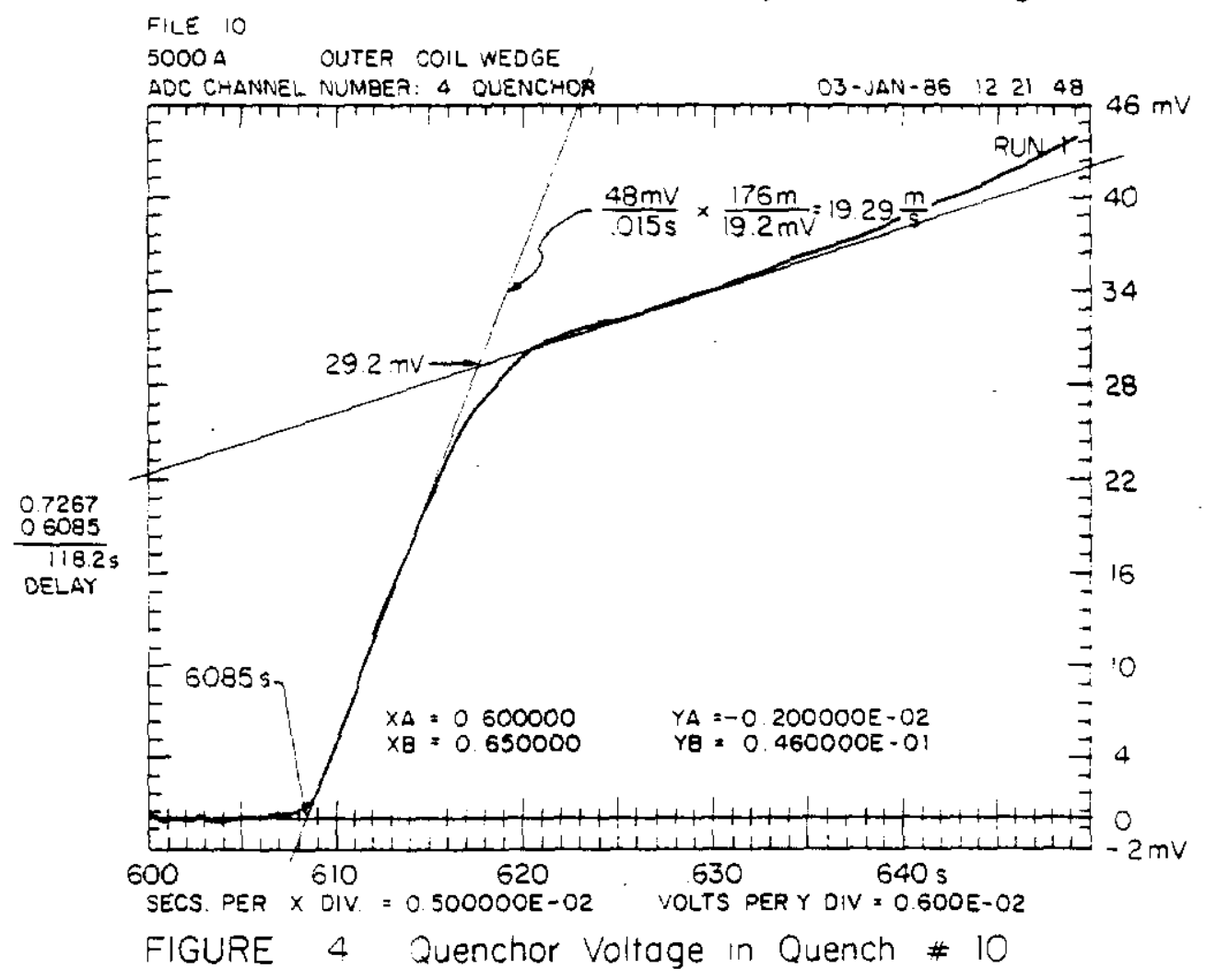

Therefore the test was not designed to accurately measure the quench progation speed in the cable itself. Nevertheless, the information obtained is relevant to our understanding of how different mechanisms contribute to the quench propagation.

The considerably lower propagation speed in the guards reflects the facts that they are close to the quench-stoppers and that they are exposed to the $4.2 \mathrm{~K}$ liquid without any insulation. The propagation speed of the quenchor involves two normal zones edges moving away from 

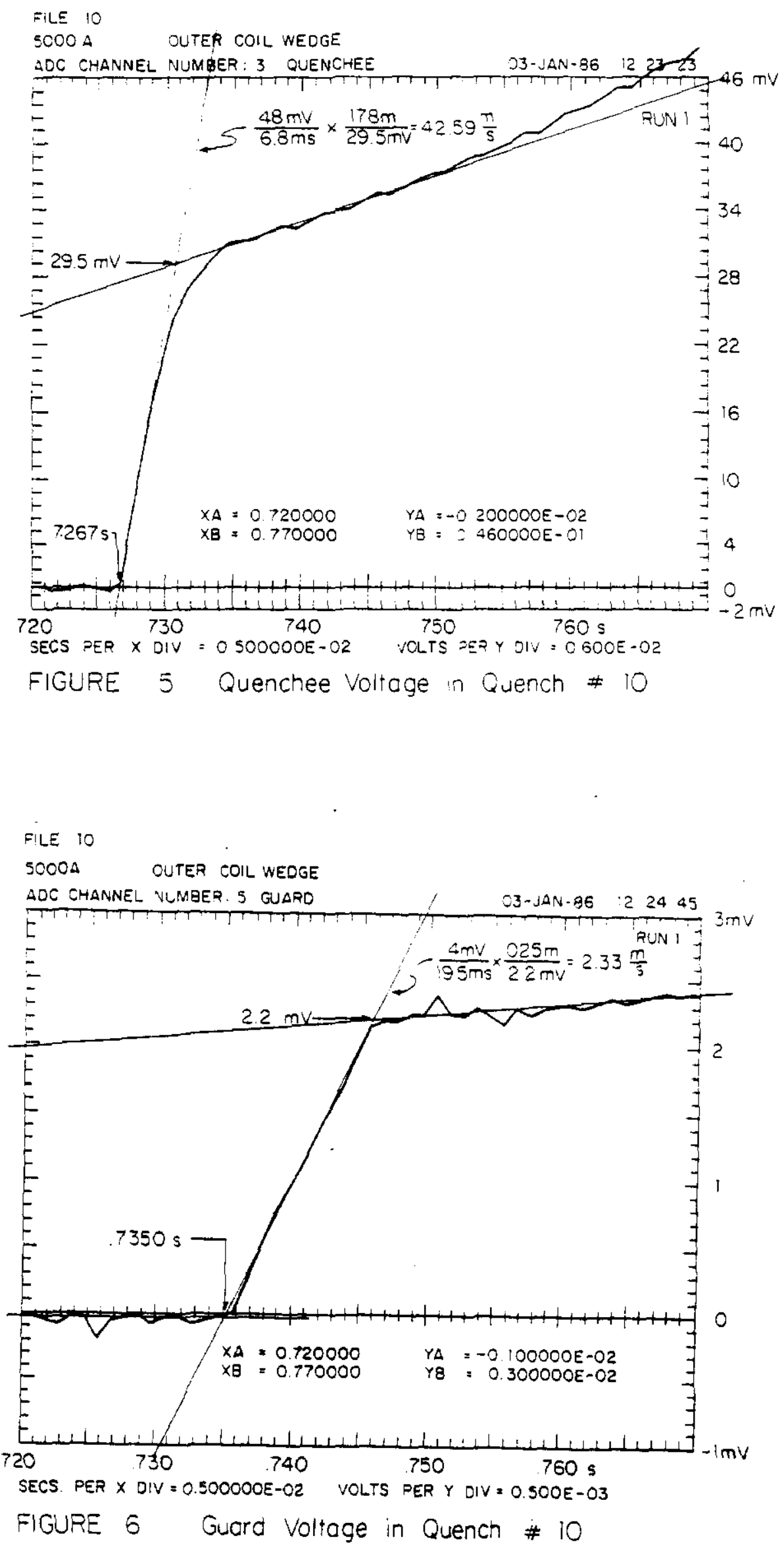
the center, so the speed of the normal zone edge is half ine indicated value. The higher propagation speed of the quenchee reflects the broadside heating reaching it through the wedge and therefore is not immediately interpretable as twice the velocity of a normal zone edge. However it could be interpreted as such but at a higher temperature.

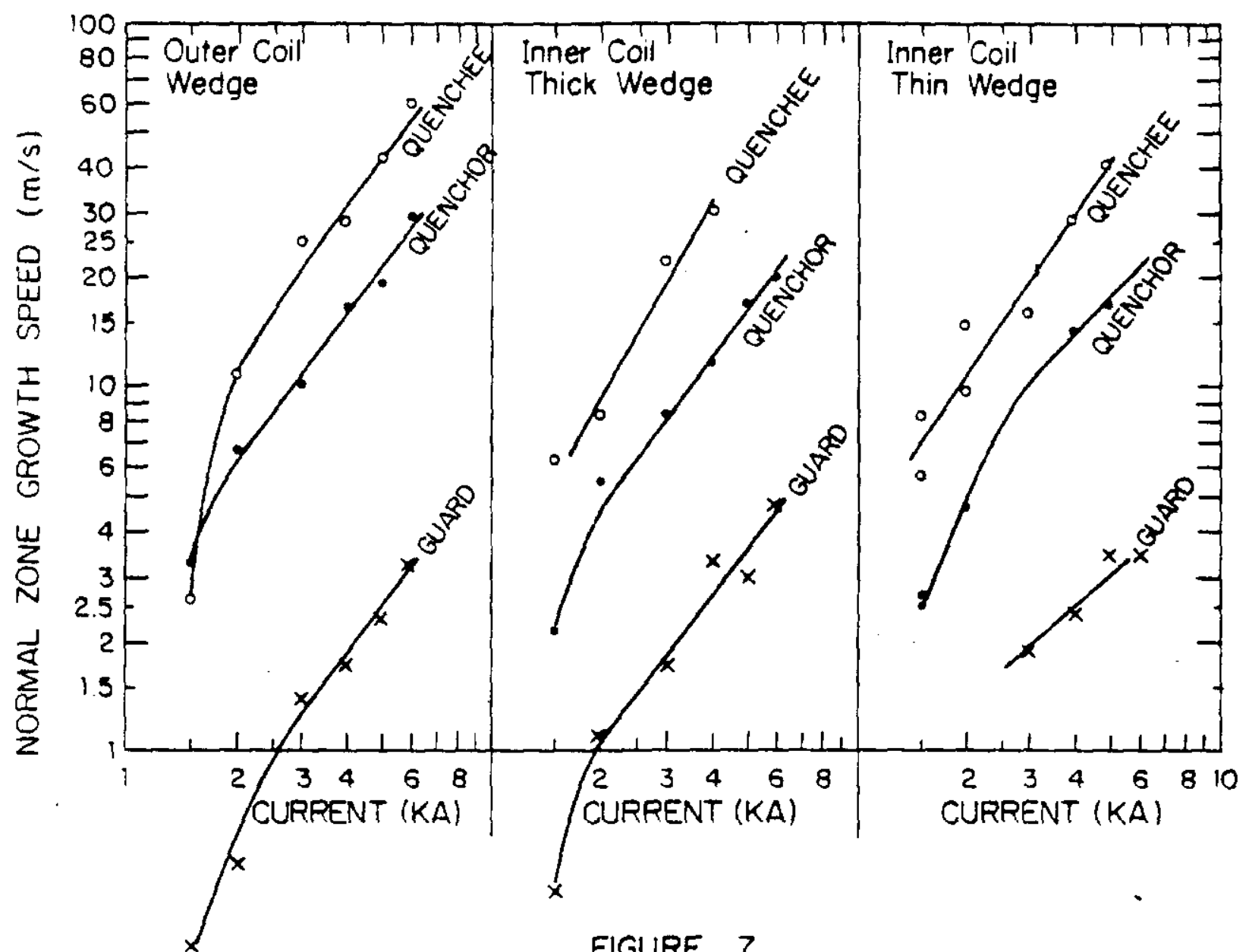

FIGURE 7

Quench Speed Doto

Figure 8 presents the observed delays between the start of a spot neater induced quench in the quenchor and the corresponding beginning of a quench in the quenchee as a function of the circulating current. The accuracy of this data is better than $2 \%$ and an excellent agreement was observed between the two instruments measuring it (chart recorder and M10 data acquisition system). For the inner coil thin wedge at $6 \mathrm{kA}$ and thick wedge at $5 \mathrm{kA}$ and $6 \mathrm{kA}$ we were precluded from using the data by the guard indication that the quenchee was triggered via the guard. 


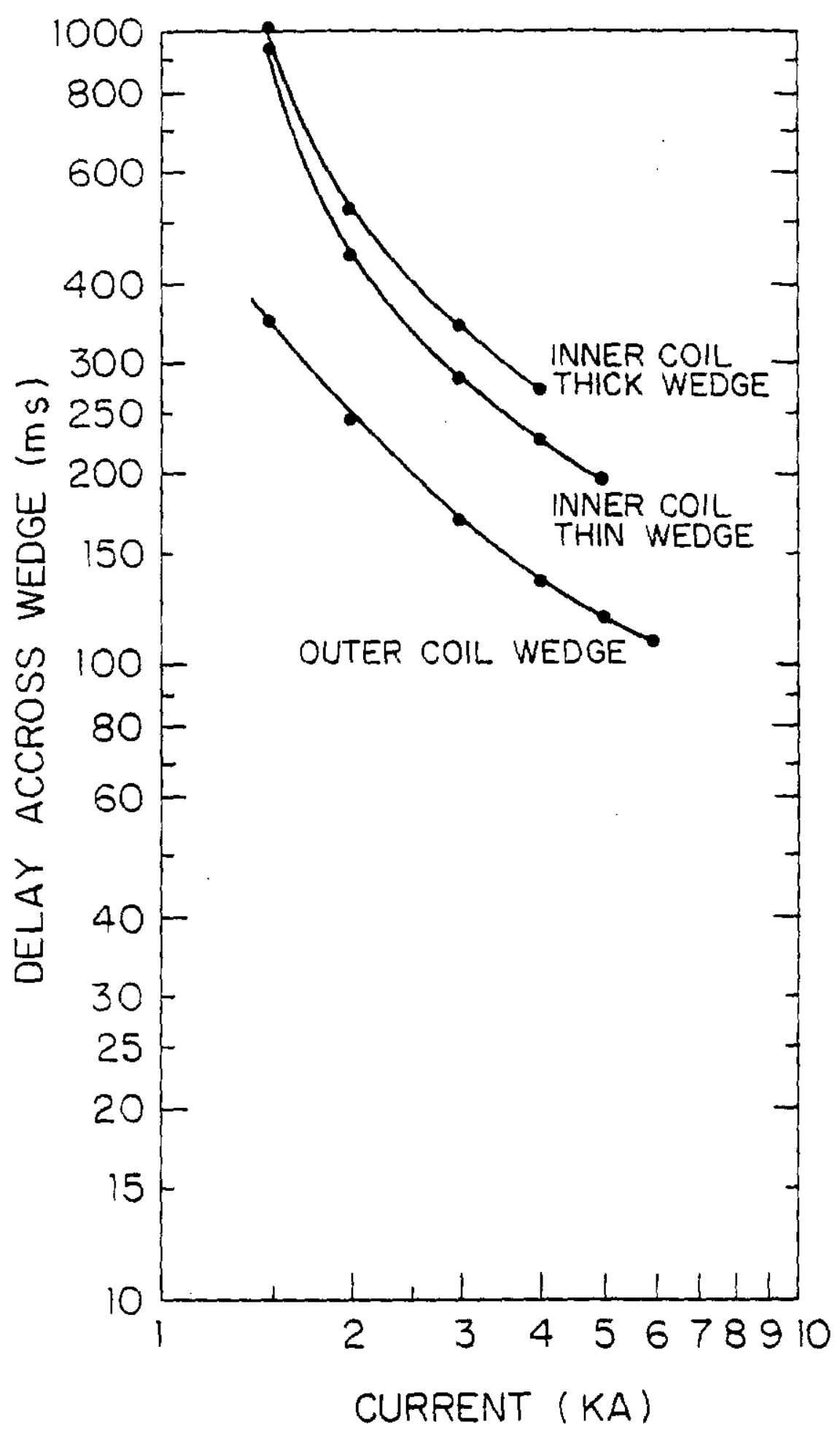

FIGURE 8

Delay in Quench Propagation Across Wedges. 
CONCLUSIONS

The observed delays indicate that the wedges can act as barriers to the fast and safe normalisation of the magnet. A near doubling of the logitudinal propagation speed as the the quench propagates transversely from cable to cable has been observed previously ${ }^{2}$. This doubling is still observed as the quench propagates transversely across a wedge. Studies involving the effect of the magnetic field and concurrent measurement of delays from cable to cable with and without wedges are still needed for proper safety design.

\section{ACKNOWLEDGEMENTS}

The expertise of $C$. Hess in instrumenting the model and of R. Nehring in setting up and carrying out the data taking operation are greatly appreciated. The model construction was done under the able supervision of R.Bossert and J.Carson. The performance of the tests in Lab 2 was ably assisted by $D$. Wendt and C.Ioriatti. We appreciated discussions with K.Koepke and we thank H.E.Fisk for his interest.

\section{REFERENCES}

1. Magnet Selection Advisory Panel Report. E. Sciulli chalrman. Sept. 9,1985

2. J.G. Cottingham, Quench Performance of the $16.6 \mathrm{~m}$ SSC Magnet Computed from Measured Data. SSC Tecnical Note No. 35 (SSC-N-47) Oct 7,1985

3. W. Hassenzahl, Predicted Quench Voltages and Required Test Voltages for SSC. SSC-MAG-58 Nov 1985.

4. G. Tool, R. Flora, P. Martin and D. Wolff, IEEE Transactions on Nuclear Science, NS-30, 2889 (1983).

5. Clyde Taylor, private communication.

6. Strain gauge model EA-06-250BE-350 Micromeasurements, Romulus, MI 48174

7. RTV sealant. Manufactured by General Electric.

8. J.E. Paschnik, Write-up of M10 program - Fermilab 1985 (unpublished) 